\title{
Gordura de frango: alternativas tecnológicas e nutricionais
}

\section{Chicken fat: technological and nutritional alternatives}

\author{
Graciela Salete Centenaro ${ }^{1 *}$; Valcenir Júnior Mendes Furlan²; \\ Leonor Almeida de Souza-Soares ${ }^{3}$
}

\begin{abstract}
Resumo
Nos últimos anos a produção de carne de frango tem aumentado expressivamente, e como conseqüência tem sido gerada uma maior quantidade de resíduos industriais provenientes do processamento das aves. Estes resíduos agroindustriais são ricos em diversos nutrientes que podem ser utilizados "in natura", mas também podem ser aplicadas técnicas de processamento a fim de proporcionar transformações desejadas sobre as características químicas e físicas, tendo em vista um melhor aproveitamento dos mesmos. Estes subprodutos são ricos em lipídios podendo ser utilizados em diversos produtos, porém geralmente são utilizados na elaboração de rações animais e produtos com baixo valor agregado. Nesta revisão estão sendo abordados os principais aspectos tecnológicos e nutricionais apresentados pelos lipídios derivados da indústria processadora de frango. Alternativas tecnológicas também são apresentadas para solucionar a questão do descarte desse material no meio ambiente.
\end{abstract}

Palavras-chave: Biocombustível, meio ambiente, resíduos agroindustriais

\begin{abstract}
In the last years the production of chicken meat have increased considerably, and as consequence have been generated a larger amount of industrial waste of the poultry processing. These agroindustrial residues are rich in several nutrients that can be used in nature, but may also be applied processing techniques in order to provide transformations desired on the chemical and physical characteristics, in view to a better use of the same ones. These by-product are rich in lipids could be used in several products, however are usually used in the elaboration of animal feed and products with low value. In this review are being approached the principal technological and nutritional aspects presented by the derived lipids of the chicken processing. Technological alternatives are also presented to solve the discard of that material in the environment.
\end{abstract}

Key words: Biofuel, environment, residues agroindustrial

1 Discente do Programa de Pós-Graduação em Engenharia e Ciência de Alimentos (FURG). E-mail: gracentenaro@yahoo.com. br.

2 Discente do Programa de Pós-Graduação em Engenharia e Ciência de Alimentos (FURG).

3 Professora Colaboradora do Programa de Pós-Graduação em Engenharia e Ciência de Alimentos (FURG).

* Autor para correspondência 


\section{Introdução}

Os hábitos alimentares do homem moderno vêm sofrendo alterações e acompanhando o progresso tecnológico das indústrias alimentícias, que lançam cada vez mais produtos no mercado. A crescente expansão da produção de carne de frango no Brasil impõe à indústria avícola a necessidade de melhorar a qualidade das carcaças colocadas à disposição dos consumidores.

Entendendo como qualidade o conjunto de atributos que condicionam a aceitação de um produto pelo consumidor, esta pode ser comprometida pela presença da gordura na carcaça, gordura abdominal encontrada na região próxima à cloaca ou a grande quantidade de pele, principalmente a de cobertura do peito. O grande impasse seria qual o destino a ser dado a este material pelo abatedouro, já que a utilização de subprodutos de origem animal está sendo atualmente retirada das dietas animais, tornando-se um produto com potencial poluente (RODRIGUES et al., 2005).

A carne de aves é considerada de boa qualidade nutricional pelo seu alto teor protéico, baixo teor de colesterol e ácidos graxos saturados. É um alimento de fácil digestão, sendo indicado na alimentação infantil, de pessoas idosas e convalescentes (MORAES et al., 1987). Com o aumento da demanda da carne de frango, consumida principalmente em corte, a gordura retirada da cavidade abdominal tem sido considerada um subproduto.

O trato inadequado dos resíduos industriais também contribui para o agravamento dos problemas ambientais, pois os produtos, que não podem ser transformados em farinhas, por exemplo, são lançados nos rios, o que leva, conseqüentemente, a poluição, cujas conseqüências são conhecidas. Por isso, é preciso minimizar os resíduos gerados, antes mesmos destes chegarem à graxaria das indústrias. As práticas de minimização de resíduos são economicamente vantajosas, pois oferecem uma possibilidade de economizar produtos e processos para tratá-los, tendo em vista o controle ambiental.

\section{Consumo e Produção de Frango}

O Brasil é o terceiro maior produtor e líder mundial nas exportações, ocupando $40 \%$ do mercado mundial de carne de frango. A produção total brasileira de carne de frango atingiu cerca de 10,3 milhões de toneladas em 2007. A estimativa de produção para 2008 é de 10,8 milhões de toneladas, ou seja, um incremento de aproximadamente $6 \%$ sobre a produção de 2007. É o segundo produto nas exportações do agronegócio e o sexto na pauta de exportações do país. No Brasil, estimase a geração de mais de 4 milhões de empregos na cadeia produtiva (UNIÃO BRASILEIRA DE AVICULTURA - UBA, 2008).

O Brasil apresenta um dos maiores índices de consumo médio de frango por habitante, que se elevou de 12,7 para $37,8 \mathrm{~kg}$ entre 1989 e 2007, ficando atrás dos Estados Unidos (ASSOCIAÇÃO BRASILEIRA DOS PRODUTORES E EXPORTADORES DE FRANGOS - ABEF, 2007). Isso se deve ao preço mais baixo em relação ao das carnes bovina e suína, pela estabilidade promovida pelo plano real e pela diversidade e praticidade dos produtos oferecidos, associadas ao conceito de um produto saudável (MARTINS; TALAMINI; NOVAES, 2007).

Mesmo no mercado doméstico o consumo de cortes e elaborados vem tirando espaço do frango inteiro. No entanto, a crescente demanda das carnes de suínos e aves, gerou aumento no consumo de carnes em geral. Entre 1998 e 2006, as carnes de frangos e suínos tiveram o consumo aumentado em aproximadamente $58 \%$ e $23 \%$ respectivamente, enquanto que, no mesmo período, o consumo de carne bovina teve aumento de apenas 13\% (UNITED STATES DEPARTMENT OF AGRICULTURE - USDA, 2007). Os brasileiros aumentaram o consumo de carne de frango de 4,24 em 1998 para 6,62 milhões de toneladas em 2006, com previsão de 7,3 milhões de toneladas em 2008 (ABEF, 2007). É a segunda carne mais consumida, ficando atrás apenas da carne bovina.

O consumo mundial não teve a mesma taxa de 
crescimento observada no Brasil. Isso é mais uma prova da competitividade da avicultura brasileira que vem ampliando sua participação nas exportações. De qualquer forma o Brasil é o terceiro maior produtor e responsável por $15,6 \%$ da produção mundial, ficando atrás dos Estados Unidos com 27,1\% e da China com 17,5 \%. Analisando a evolução da produção brasileira em cada região, nos últimos 10 anos verifica-se que elas não tem apresentado os mesmos índices de crescimento. A região sul, pioneira na avicultura, teve um incremento de $133 \%$ na sua produção e aumentou de 50 para $56 \%$ sua participação na produção brasileira. A região centro-oeste é a mais recente área de expansão da avicultura. Esta região tem apresentando o maior crescimento da produção (306\%) e também dobrou ( $5 \%$ para $10 \%$ ) sua participação na produção brasileira, ultrapassando a região nordeste e se colocando como a terceira maior região produtora. O sudeste ainda ocupa a segunda posição embora esteja perdendo participação. As regiões norte e nordeste, devido aos pequenos volumes produzidos e custos mais elevados da alimentação das aves, têm uma pequena participação na produção nacional (ABEF, 2007).

A exportação de frangos alcançou em 2007 um total de 3,2 milhões de toneladas. Nos primeiros quatro meses de 2008 já foi exportado 1,150 milhão de toneladas, um volume $14,02 \%$ superior ao de igual período de 2007. Em receita, as vendas externas somaram US\$ 2,042 bilhões, um crescimento de $51,4 \%$ ante o primeiro quadrimestre de 2008. De acordo com a ABEF (2007), para 2008, a evolução de preços das carnes deverá continuar, já que se esperam altas nos preços, tanto para o mercado interno como para o externo.

\section{Geração de Resíduos}

O conhecimento das quantidades geradas e as principais características físicas e químicas dos resíduos agroindustriais é fundamental para a concepção e o dimensionamento dos sistemas de tratamento para disposição na natureza e, ou reaproveitamento desses resíduos (MATOS, 2005).

Cadavezmais o processo de seleção e cruzamentos entre raças tem se aprimorado, resultando na descaracterização das mesmas, originando linhagens específicas, com características próprias. As aves destinadas à produção de carne, conhecidas como frango de corte têm sido selecionadas principalmente para características de desempenho, o que proporcionou avanços na taxa de crescimento dos animais. Contudo a seleção intensa para essas características levou também a um aumento na proporção e quantidade de gordura nessas aves, além de provocar alterações no tamanho, na forma e na função dos órgãos desses animais (GAYA, 2003). Nos matadouros de bovinos são produzidos cerca de $23 \mathrm{~kg}$ de barrigada e $18 \mathrm{~kg}$ de dejetos, para cada animal abatido, enquanto nos abatedouros de frango o descarte de material (penas, intestinos, pé, cabeça, pele e sangue) representa $30 \%$ da massa total do animal (MATOS, 2005). O teor de gordura em uma carcaça de frango de corte pode ser influenciado por diversos fatores, como origem genética, idade da ave, sexo, sendo que as fêmeas apresentam uma maior quantidade de gordura que os machos. Além disso, a quantidade de gordura ainda tem uma correlação positiva com o peso vivo da ave. As linhagens modernas vêm sendo trabalhadas para um rápido ganho de peso e deposição protéica, sendo que quando houver qualquer desbalanço no fornecimento dos nutrientes a deposição de gordura abdominal é aumentada. Esta gordura é gerada através da hipertrofia e hiperplasia das células adiposas (RODRIGUES et al., 2005).

A deposição excessiva não apenas reduz o rendimento da carcaça e a eficiência alimentar das aves, mas também leva o consumidor à rejeição da carne de frango, visto que o mercado de hoje exige uma carne magra (GAYA, 2003). A gordura abdominal corresponde a aproximadamente 2 a $2,5 \%$ do peso total do frango abatido (PERDIGÃO AGROINDUSTRIAL, 2000). Esta gordura pode ser aproveitada como um ingrediente na fabricação 
de rações e embutidos, pois apresenta altos teores de ácido oléico, palmítico e linoléico. Contudo, os pequenos abatedouros a descartam, juntamente com as vísceras, penas e sangue contribuindo, desta forma, com o aumento dos dejetos lançados na natureza (CHIU; GIOIELLI, 2002). A utilização deste material gorduroso para produção de ração animal, sabão, ou como fonte para produção de energia, como o biocombustível, aparece como uma excelente alternativa para a indústria, com grande apelo quando relacionado à preservação do meio ambiente. A pele oriunda da desossa de frangos de corte também pode ser submetida a processamento térmico industrial para ser posteriormente utilizada na industrialização de produtos cárneos destinados ao consumo humano (FRANÇA; WASZCZYNSKYJ, 2002).

\section{Gordura de frango para produção de ração animal}

Óleos e gorduras são ingredientes muito utilizados nas rações como fonte concentrada de energia, permitindo a formulação de dietas de elevado conteúdo energético para frangos de corte (RACANICCI et al., 2004). Dietas para frangos de corte formuladas apenas com matériasprimas habituais, como milho e farelo de soja, não permitem alcançar os níveis energéticos recomendados. Neste sentido, para elevar os níveis de energia metabolizável, são adicionados às rações, subprodutos de origem animal e vegetal (FERNANDES et al., 2002), como uma alternativa de aproveitamento desses resíduos de baixo custo, que quando descartados podem causar sérios danos ao meio ambiente. Mas nem sempre a utilização desses subprodutos é vantajosa.

A indústria avícola tem utilizado em larga escala subprodutos de abatedouros adicionados às rações, como o óleo de vísceras de aves, que tem como principal vantagem o baixo custo e o alto conteúdo energético já mencionado. No entanto, o perfil de ácidos graxos deste óleo favorece o desenvolvimento da rancidez oxidativa devido à grande quantidade de ácidos graxos insaturados, principalmente os ácidos oléico (C18:1) e linoléico (C18:2). Os efeitos negativos do fornecimento do óleo oxidado na dieta sobre o desempenho de frangos de corte já foram muitas vezes demonstrados e acredita-se que a redução do crescimento pode ser atribuída à presença dos produtos da oxidação, que levam a valores reduzidos de energia da dieta pelo decréscimo do valor biológico do ingrediente oxidado (RACANICCI et al., 2004).

Dentre os aspectos mais importantes na decisão de qual tipo de lipídio utilizar para a formulação de rações para frangos de corte estão o custo e a qualidade das respectivas fontes e quais os seus efeitos sobre o desempenho e a qualidade da carcaça (ZOLLITSCH et al., 1997 apud LARA et al., 2006). Do ponto de vista de qualidade, dependendo da fonte lipídica utilizada, sua origem e composição em ácidos graxos, pode modificar o perfil dos mesmos, por exemplo, com ácidos graxos de melhor valor nutricional, produzindo, dessa forma, alimentos funcionais, ou seja, alimentos que além de suas características nutritivas trazem outros benefícios aos consumidores. A composição de ácidos graxos da gordura abdominal, músculo do peito e da coxa pode ser manipulada mediante mudança da composição destes na dieta através da formulação da ração (SCAIFE; MOYO; GALBRAITH, 1994).

\section{Produção de sabão a partir de gordura de frango}

Além de serem aproveitados para fabricação de ração animal, os resíduos e a gordura da industrialização do frango também são utilizados nas indústrias de sabão (GALÃO; PINTO; BORSATO, 2003). Um estudo da composição dos ácidos graxos da gordura e a sua capacidade de saponificação foi desenvolvido por Galão, Pinto e Borsato (2003), a fim de obter um sabão de baixo custo, fácil fabricação e útil para limpeza em geral. Após derivatização, os autores realizaram a identificação dos ácidos graxos nos produtos obtidos, através de espectrômetro de 
massa por impacto eletrônico. Eles concluíram que o estudo da gordura por cromatografia gasosa, após derivatização dos ácidos presentes, indicou a presença predominante de ácidos graxos insaturados, e 45,27\% da parte injetada no cromatógrafo correspondiam a colesterol. Devido ao alto teor de colesterol apresentado pela gordura de frango, analisada pelos autores, não se recomenda o uso dessa gordura na alimentação humana ou animal, mas a reação dessa gordura, com uma solução aquosa de hidróxido de sódio, forneceu um sabão de boa qualidade. Dessa forma, os rejeitos dos abatedouros de frangos, ricos em gordura, podem ser aproveitados para a produção de sabão pelas indústrias saboeiras (GALÃO; PINTO; BORSATO, 2003).

\section{Fracionamento de gordura de frango}

As gorduras são invariavelmente misturas de diferentes triacilgliceróis e cada um destes apresenta seu próprio ponto de fusão. Portanto, as gorduras não apresentam um ponto de fusão específico, mas sim uma faixa de fusão (CHIU; GIOIELLI, 2002). O fracionamento de óleos e gorduras é uma forma de processamento na qual os triacilgliceróis, que compõem um certo óleo, são separados em frações de ponto de fusão e composições diferenciadas. É um processo de modificação completamente reversível que envolve uma cristalização parcial seguida da separação por filtração das frações sólidas e líquidas (PARMENTIER, 2000). As diferenças resultantes nas frações dependem das características e dos parâmetros de ajuste do processo, enquanto que a eficiência da separação do líquido (oleína) da fase cristalina (estearina) influencia a qualidade da fração sólida. Segundo Hamm (1995), o fracionamento é utilizado com o objetivo de alcançar um ou mais desses três objetivos:

(a) remoção de pequenas quantidades de compostos de alto ponto de fusão, como os triacilgliceróis de ácidos graxos saturados, de modo que o mesmo se torne límpido, prevenindo a solidificação de alguns componentes a baixas temperaturas. Essa aplicação é conhecida como "winterização";

(b) enriquecimento de um óleo com um triacilglicerol mais insaturado, objetivando melhorar suas propriedades de aplicação, quando usado como óleo liquido ou em composições com outros óleos ou gorduras;

(c) recuperação de uma fração com uma composição aproximada e propriedades de fusão rápida. Apropriados para uso em chocolates e produtos de confeitaria, assim como gorduras de cobertura. Esse processo de fracionamento via seca, chamado de "winterização, busca separar aqueles triacilgliceróis de mais alto ponto de fusão (causadores da turvação), baseado na sua precipitação na forma de cristais, sob determinadas condições de temperatura e tempo. A partir desse processo obtêm-se, então, produtos mais selecionados, como óleo comestível de baixo ponto de turvação, oleínas de alto índice de iodo, estearina e ácido esteárico (CUNHA et al., 2002).

O processo de fracionamento a seco da gordura envolve a homogeneização, a cristalização seletiva dos triacilgliceróis de elevado ponto de fusão, na qual três fatores, temperatura, tempo e agitação, têm importância fundamental sobre a natureza e formação dos cristais, seguida por filtração. Isto conduz a separação de uma fração sólida (estearina) com um conteúdo elevado de ácidos graxos saturados e uma fração líquida (oleína) com um elevado conteúdo de ácidos graxos insaturados. $\mathrm{Na}$ homogeneização a gordura é aquecida a uma temperatura superior ao seu ponto de fusão, para ser lentamente resfriada na etapa seguinte, de cristalização, na qual as moléculas de triglicerídeos, em constante movimento, aproximam-se umas das outras, e vão atraindo mais dessas moléculas até a formação de cristais que se estabilizam. $\mathrm{Na}$ última etapa, os cristais são separados por via seca (filtração) ou por via úmida (centrifugação).

O fracionamento a seco é atualmente usado no processamento de uma ampla série de gorduras 
(óleo de palma, gordura de leite, óleo de pescado, gordura animal, etc.) com o objetivo de eliminar a maioria dos compostos saturados, aumentando o conteúdo de ácidos graxos insaturados, como mencionado anteriormente ou então a obtenção frações com propriedades reológicas especiais. A gordura de frango é uma gordura semi-sólida em seu estado natural com boas propriedades nutricionais comparadas com outras gorduras de origem animal e o seu fracionamento a seco, resulta em uma fração sólida gordurosa, cujas características físicas se assemelham as da banha e do sebo. (ARNAUD et al., 2004).

Em face disso, uma alternativa para potencializar a obtenção de produtos mais nobres, a partir da gordura de frango é o processo de fracionamento. Além da mistura, o fracionamento é o método mais econômico no processamento de lipídios, pois se trata de um processo puramente físico, comparado às modificações químicas tais como a hidrogenação e a interesterificação, que alteram os triacilgliceróis. As interações que ocorrem entre os triacilgliceróis nas misturas promovem alterações nas propriedades físicas das gorduras (CHIU; GIOIELLI, 2002).

O fracionamento a seco é o processo mais conhecido atualmente, já que o investimento inicial e os custos de exploração são baixos, não são utilizados reagentes e não há perdas de produto. Comparado aos processos de fracionamento com detergente e com solvente, o fracionamento a seco apresenta algumas vantagens como: simplicidade do sistema, ausência de resíduos nas frações, menor número de aquecimento das frações, não necessita de mão de obra especializada (TRUJILLO-QUIJANO; ESTEVES; WIRTH, 1988).

Ferrari e Koller (2001), estudaram o processo de fracionamento a seco de gordura de frango onde obtiveram duas frações para cada processo de fracionamento, uma fração oleína (menor ponto de fusão) e estearina (maior ponto de fusão) e verificaram que houve diferença no ponto de fusão das frações obtidas pelos sucessivos processos de fracionamento aplicados, com variação entre 22 e $38^{\circ} \mathrm{C}$. A partir da matéria-prima inicial, foram obtidos seis produtos: oleína, estearina, oleínaoleína, oleína-estearina, estearina-oleína e estearinaestearina, com pontos de fusão diferente da matériaprima original. Os autores também observaram uma elevação no teor total de ácidos graxos insaturados nas frações oleína e de ácidos graxos saturados nas estearinas, comprovando a eficiência do processo neste sentido. As amostras de estearinas, além de apresentarem um comportamento mais sólido, tem também acrescida sua estabilidade oxidativa, em virtude da diminuição do teor de ácidos graxos insaturados, susceptíveis a esta degradação o que amplia a gama de aplicação destes produtos que poderão ser utilizados na produção de gorduras especiais, ou como ingrediente em formulações de alimentos, desta forma agregando valor a um produto atualmente considerado resíduo agroindustrial.

\section{Produção de biocombustível a partir de gordura de frango}

O biodiesel, nome genérico dado a combustíveis e aditivos derivados de fontes renováveis, como óleos vegetais e gorduras animais, é uma aposta para o futuro em duas direções. Uma delas visa minimizar o impacto da redução na oferta do petróleo sobre a economia. A segunda é ambiental, já que o biodiesel é bem menos poluente (SOUZA, 2006). Após várias oscilações nos preços do petróleo e derivados, percebeu-se a necessidade de fontes energéticas alternativas. Uma das opções é o biodiesel, um combustível renovável, que pode ser obtido a partir de óleos vegetais ou de rejeitos gordurosos. $\mathrm{O}$ uso de óleos vegetais em motores de combustão interna começou com Rodolf Diesel utilizando óleo de amendoim em 1900. Razões de natureza econômica levaram ao completo abandono dos óleos vegetais como combustíveis na época. Entretanto, na década de 70, o mercado de petróleo foi marcado por dois súbitos desequilíbrios entre oferta e demandas mundiais conhecidos como 
$1^{\circ}$ e $2^{\circ}$ Choques do Petróleo. Em respostas a estas crises, o mercado sentiu a necessidade de diminuir a dependência do petróleo, levando ao investimento no desenvolvimento de tecnologia de produção e uso de fontes alternativas de energia (OLIVEIRA, 2005).

A busca por combustíveis alternativos ao petróleo se transformou nos últimos anos em objetivo comum de centros de pesquisa em todo o mundo. O Brasil é um dos países com mais resultados nesta área e utiliza há décadas o álcool combustível em automóveis. Como existe o risco de restrições quanto ao uso da gordura animal na fabricação de ração, a produção de biodiesel passa a ser uma alternativa viável para dar um destino correto a este resíduo (SOUZA, 2006).

O biodiesel é obtido a partir de misturas de óleos vegetais e álcool e a reação é catalisada por soda cáustica, ou outros catalisadores alcalinos. O produto obtido apresenta-se contaminado por glicerol, e por isso torna-se necessária uma purificação apropriada da mistura resultante (SANT'ANNA, 2003). No estudo de Rodrigues et al. (2005), os autores analisaram o rendimento de carcaças comuns de quatro diferentes marcas comerciais de frango, obtidas no mercado da região sudeste do Brasil. O peso médio das carcaças esteve em torno de 2,4 $\mathrm{kg}$, e a gordura abdominal presente na carcaça, que é geralmente descartada pelo consumidor foi de aproximadamente 34 gramas.

Ao avaliar as diferentes marcas de frango, verificou-se um rendimento de gordura abdominal variou de $1 \%$ a $1,8 \%$ (24 a 43 gramas). Considerando-se que a produção brasileira no ano de 2006 se aproximou dos 9,3 milhões de toneladas a produção de gordura abdominal descartada pode variar de 93.000 a 167.000 toneladas, material este que poderia ser utilizado como matéria prima para a produção de biodiesel, representando hoje cerca de 10 a $16 \%$ da necessidade do B2 (combustível comercial composto de $98 \%$ em volume de óleo diesel e $2 \%$ em volume de biodiesel) (RODRIGUES et al., 2005). Com a produção de filetes de carne de frango a pele se torna um resíduo problemático na indústria avícola. Esta pele pode representar em torno de $2 \%$ da carcaça, o que renderia em torno de 1 a $1,5 \%$, ou seja, de 93.000 a 140.000 de matériaprima disponível para transformação. Considerando que a indústria de produção de filetes ainda é limitada no Brasil, e estimando que em torno de $15 \%$ da produção seja neste setor, ter-se-ia em torno de 14.000 toneladas de pele, somado a da gordura abdominal, poderiam contribuir com 12 a $20 \%$ da necessidade de matéria prima para a produção de biodiesel, para atender a legislação de B2. Por enquanto, o uso do biodiesel é opcional. Mas no futuro, passará a ser obrigatório. A partir de janeiro de 2008, todo o diesel comercializado no Brasil deverá conter $2 \%$ de biodiesel. O percentual subirá para 5\% em 2013. Apenas com a mistura de 2\%, a demanda anual será de aproximadamente 800 mil toneladas de biodiesel. Hoje, a produção brasileira chega a apenas 20 mil toneladas.

A Embrapa Suínos e Aves divulgou recentemente que pretende desenvolver nos próximos anos uma metodologia para a geração de biodiesel a partir da gordura animal proveniente de resíduos de abatedouros. A empresa também quer disponibilizar um modelo, com a sugestão de equipamentos, para transformar o biodiesel em fonte de aquecimento nas instalações usadas para a criação de suínos e aves. No Rio de Janeiro existe uma unidade piloto de produção de biodiesel na Universidade Federal, baseada em óleos de frituras usados e cuja capacidade produtiva é de 6,5 mil litros/dia. Em parceria com a UFRJ, uma indústria química fornece a matériaprima (óleos vegetais, novos e usados, e gordura animal), realiza a coleta dos 25 mil litros mensais de óleo de fritura usados e doados por uma rede de lanchonetes. Esta indústria pré-purifica o material e fornece à universidade, onde estão sendo realizados os testes de produção, enquanto investe na adaptação de sua planta de beneficiamento, a qual produzirá 200 mil litros de biodiesel por dia e utilizará a rota metílica (OLIVEIRA, 2005). 


\section{Composição Lipídica}

Assim como as demais matérias graxas de origem animal ou vegetal, fisiologicamente a fração lipídica de frango é excelente fornecedora de energia e biossíntese, além de ser responsável pelo transporte de compostos químicos lipossolúveis como ácidos graxos essenciais, vitaminas e hormônios. (FERRARI; KOLLER, 2001).

Os óleos e gorduras são constituídos de triacilgliceróis de ácidos graxos que, individualmente, em temperatura ambiente podem se apresentar no estado líquido ou sólido. Como estas frações são solúveis entre si e totalmente miscíveis, encontram-se freqüentemente óleos vegetais (líquidos) que contém frações gordurosas e vice-versa. As gorduras naturais são misturas complexas de triacilgliceróis, ácidos graxos livres, acilgliceróis parciais e componentes menores como fosfolipídios, esteróis e tocoferóis. Como a maioria da gordura é refinada, suas propriedades físicas são determinadas pelas propriedades dos triacilgliceróis (HILDITCH, 1941).

De acordo com Arnaud et al. (2004), existe um mercado crescente para $100 \%$ dos produtos avícolas, especialmente porque estes produtos não são proibidos por nenhuma religião. A gordura de frango pode ser incorporada em produtos de delicatessen como carnes e apresenta substancial valor nutritivo.

A comparação da gordura de frango com outras gorduras animais como a banha e o sebo, mostra que a gordura de frango em geral, apresenta grande proporção de ácidos graxos insaturados e polinsaturados. Devido ao alto grau de insaturação, esta gordura é semi-líquida a temperatura ambiente. O seu baixo ponto de fusão deve-se ao baixo conteúdo de ácidos graxos saturados. A literatura relativa à composição e às propriedades fisicoquímicas da gordura de frango não é extensa.

De acordo com Lee e Foglia (2000), a gordura de frango contém cerca de $60 \%$ de ácidos graxos insaturados, sendo, portanto, altamente insaturada quando comparada ao sebo bovino. Entre os ácidos graxos insaturados, os monoinsaturados (AGMI), tais como o ácido oléico, são considerados desejáveis no que tange à redução do risco de enfermidades cardiovasculares, pois reduzem os níveis de colesterol sanguíneo em indivíduos nãohipertrigliceridêmicos. Devido à importância desses ácidos graxos na dieta, tem sido recomendado que sua ingestão seja correspondente à metade do total de calorias obtidas a partir das gorduras totais. A gordura de frango é considerada uma fonte de AGMI, uma vez que apresenta teores em torno de 45 a $50 \%$, enquanto que o sebo bovino apresenta somente 30 a $40 \%$ desses ácidos graxos.

Os triacilgliceróis de cadeia média (TCM) são formados por ésteres de glicerol contendo ácidos graxos com 6 a 12 átomos de carbono. Os AGCM são absorvidos através da parede intestinal sem ressíntese dos triacilgliceróis nas células intestinais. Os TCM sofrem, predominantemente, b-oxidação e não são estocados nas células adiposas. Conseqüentemente, constituem boa fonte de energia para pacientes com insuficiência pancreática e má absorção lipídica (TSUJI et al., 2001).

A Tabela 1 apresenta os ácidos graxos que compõem a gordura de galinhas domésticas segundo Hilditch (1941). Este autor cita que o principal depósito de gordura nas aves está localizada nas regiões abdominal e da moela e que há menos gordura no tecido subcutâneo do pescoço e na pele. 
Tabela 1. Composição percentual dos ácidos graxos presentes na gordura de galinhas domésticas.

\begin{tabular}{cc}
\hline Ácidos graxos & \% em massa \\
\hline $16: 0-$ palmítico & $18,4-19,3$ \\
$18: 0-$ esteárico & $7,5-8,9$ \\
$18: 1$ - oléico & $54,7-55,4$ \\
$18: 2-$ linoléico & $17,8-17,9$ \\
\hline
\end{tabular}

No estudo de Chiu, Gioielli e Grimaldi (2008), os autores caracterizaram gordura abdominal de frango e os resultados mostraram que a gordura apresentou em sua composição principalmente os ácidos oléico (43,4\%), palmítico $(24,7 \%)$ e linoléico $(17,2 \%)$.

A gordura de frango apresenta o mesmo comportamento que o óleo de milho quanto à baixa taxa nos lipídios séricos humanos. Além disso, esta gordura possui odores e flavors naturais desejáveis, tornando seu uso adequado como ingredientes de alimentos e como base gordurosa em formulações alimentícias. Estas comparações colocam a gordura de frango em situação mais promissora que outras gorduras animais, devido ao seu uso potencial em alimentos (PEREIRA et al., 1997).

Em estudo de Viau e Gandemer (1991), eles descreveram a composição em ácidos graxos, a estrutura dos triacilgliceróis, os conteúdos de colesterol e tocoferol e a proporção de gordura sólida entre $0^{\circ}$ e $40^{\circ} \mathrm{C}$ de várias gorduras de aves, como frango, pato e ganso. Eles verificaram que as proporções relativas de ácidos graxos saturados, monoinsaturados e polinsaturados variaram, respectivamente, de $29 \%$ a $35 \%$, de $47 \%$ a $57 \%$ e de $10 \%$ a $24 \%$, de acordo com a gordura analisada. Os ácidos graxos saturados influenciam fortemente o conteúdo de gordura sólida dos lipídios, devido ao seu elevado ponto de fusão, que varia de $63^{\circ} \mathrm{C}$ a $70^{\circ} \mathrm{C}$.

Lara et al. (2006), avaliaram o efeito de diferentes fontes de lipídios da dieta (óleo degomado de soja, óleo de vísceras de aves, óleo ácido de soja, mistura de $50 \%$ de óleo de soja e $50 \%$ de óleo de vísceras e mistura de $50 \%$ de óleo de soja e 50\% de óleo ácido de soja) sobre rendimento, composição de peito, coxa e carcaça inteira e perfil de ácidos graxos da carcaça inteira de frangos de corte. Eles verificaram que as aves alimentadas com dietas com óleo de vísceras apresentaram maior percentual de ácidos graxos monoinsaturados na carcaça do que as alimentadas com dietas contendo as demais fontes lipídicas. O rendimento de carcaça, a composição da carcaça inteira, do peito e da coxa de frangos de corte não foram influenciados pela fonte lipídica. $\mathrm{O}$ perfil de ácidos graxos da gordura da carcaça inteira de frangos de corte foi influenciado pela fonte lipídica utilizada nas rações.

\section{Considerações Finais}

Os resíduos gordurosos provenientes da indústria do processamento de frango contêm propriedades bioquímicas vantajosas nutricionalmente e também boas propriedades tecnológicas. Após tratamento adequado, estes resíduos podem ser aproveitados para o desenvolvimento de um novo produto para alimentação humana, como ingrediente para alimentos já existentes, e também como combustível alternativo. A sua utilização irá depender do produto final desejado, custo e tecnologia de fabricação.

\section{Referências}

ARNAUD, E.; RELKIN, P.; PINA, M.; COLLIGNAN, A. Characterization of chicken fat dry fractionation at the pilot scale. European Journal of Lipid Science and Technology, Weinheim, v. 106, n. 9, p. 591-598, 2004.

ASSOCIAÇÃO BRASILEIRA DOS PRODUTORES E EXPORTADORES DE FRANGOS - ABEF. Estatísticas. Disponível em: <http://www.abef.com.br/estatísticas. $\mathrm{htm}>$. Acesso em: 10 maio 2007. 
CHIU, M. C.; GIOIELLI, L. A. Conteúdo de gordura sólida da gordura abdominal de frango, de suas estearinas e de suas misturas binárias com toucinho. Ciência e Tecnologia de Alimentos, Campinas, v. 22, n. 2, p. 151157, 2002.

CHIU, M. C.; GIOIELLI, L. A.; GRIMALDI, R. Lipídios estruturados obtidos a partir da mistura de gordura de frango, sua estearina e triacilgliceróis de cadeia média: I- Composição em ácidos graxos e em triacilgliceróis. Química Nova, São Paulo, v. 31, n. 2, p. 232-237, 2008.

CUNHA, D. C.; SARAIVA, D. P.; DAOUD, R.; PINTO, L. A. A. Estudo do fracionamento físico do óleo de pescado via "Winterização". Brazilian Journal of Food Technology, Campinas, v. 5, n. 97, p. 183-188, 2002.

FERNANDES, J. I. M.; FREITAG, A.; ROCHADELLI, R.; BURIN, A. M.; CORDEIRO, C. P. Resíduo gorduroso da indústria de óleos vegetais em substituição ao óleo de soja em rações para frangos de corte. Archives of Veterinary Science, Curitiba, v. 7, n. 2, p. 135-141, 2002.

FERRARI, R. A.; KOLLER, F. R. Fracionamento de gordura de frango. Publicatio UEPG, Ponta Grossa, v. 7, n. 1, p. 43-51, 2001.

FRANÇA, J. M.; WASZCZYNSKYJ, N. Teor de hidroxiprolina em peles de frango submetidas à tratamento térmico. Boletim do CEPPA, Curitiba, v. 20, n. 1, p. 1928, jan./jun. 2002.

GALÃO, O. F.; PINTO, J. P.; BORSATO, D. Análise e aproveitamento da gordura de resíduos de abatedouros de aves. Semina: Ciências Exatas e Tecnológicas, Londrina, v. 24, p. 93-96, dez. 2003.

GAYA, L. G. Estudo genético da deposição da gordura abdominal e das características de desempenho, carcaça e composição corporal em linhagem macho de frangos de corte. 2003. Dissertação. (Mestrado em Zootecnia) - Universidade de São Paulo, São Paulo.

HAMM, W. Trends in edible oil fractionation. Trends in Food Science and Technology, Cambridge, v. 6, n. 4, p. 121-126, Apr. 1995.

HILDITCH, T. P. The chemical constitution of natural fats. New York: John Wiley and Sons, 1941.

LARA, L. J. C.; BAIÃO, N. C.; AGUILAR, C. A. L.; CANÇADO, S. V.; FIUZA, M. A.; RIBEIRO B. R. C. Rendimento, composição e teor de ácidos graxos da carcaça de frangos de corte alimentados com diferentes fontes lipídicas. Arquivo Brasileiro de Medicina Veterinária e Zootecnia, Belo Horizonte, v. 58, n. 1, p. 108-115, 2006.
LEE, K. T.; FOGLIA. T. A. Synthesis, purification, and characterization of structured lipids produced from chicken fat. Journal of the American Oil Chemists Society, Chicago, v. 77, n. 10, p. 1027-1034, 2000.

MARTINS, F. M.; TALAMINI, D. J. D.; NOVAES, M. Avicultura: situação e perspectivas brasileira e mundial. Concórdia/SC: Embrapa Suínos e Aves. Disponível em: $<$ http://www.aveworld.com.br/index. php?documento=1415>. Acesso em: 10 maio de 2007 .

MATOS, A. T. Curso sobre tratamento de resíduos agroindustriais. Viçosa: FEAM/UFV, 2005.

MORAES, M. C. S.; BARROSO, M. A. T.; ZAPATA, J. F.; FUENTES, M. F. Estudo comparativo da gordura de capote, galinha caipira e frango de granja. Boletim da Sociedade Brasileira de Ciência e Tecnologia de Alimentos, Campinas, v. 21, n. 1, p. 15-24, 1987.

OLIVEIRA, S. M. M. Produção de biodiesel. In: INSTITUTO DE TECNOLOGIA DO PARANÁ - TECPAR. Sistema brasileiro de respostas técnicas Ministério da Ciência e Tecnologia. Curitiba: TECPAR, 2005.

PARMENTIER, M. Fractionations of fats - a dossier. European Journal of Lipid Science and Technology, Weinheim, v. 102, n. 3, p. 233-248, Apr. 2000.

PERDIGÃO AGROINDUSTRIAL S. A. Abatedouro de Aves, Unidade Videira. Garantia da qualidade. Santa Catarina, 2000. Comunicação Pessoal.

PEREIRA, A. S.; MIKULSKI, J.; PRATT, D. E.; STADELMAN, W. J. A comparison of quality of chicken fried in vegetable oil, chicken fat or duck fat. Poultry Science, Champaign, v. 56, p. 370-373, 1997.

RACANICCI, A. M. C.; MENTEN, J. F. M.; REGITANOD'ARCE, M. A. B.; GAIOTTO, J. B.; LONGO, F. A.; PEDROSO, A. A.; SORBARA, J. O. B. Oxidação lipídica do óleo de vísceras de aves para redução de seu conteúdo de energia metabolizável para frangos de corte na fase de crescimento. Revista Brasileira de Zootecnia, Viçosa, v. 33, n. 4, p. 919-923, 2004.

RODRIGUES, K. F.; FRAGA, A. C.; NETO, P. C.; MACIEL, J. A. S.; LOPES, O. C. Potencialidade da gordura de frango para a produção de biodiesel. Biodiesel: o novo combustível do Brasil. In: CONGRESSO DA REDE BRASILEIRA DE TECNOLOGIA DO BIODIESEL, 1., 2005, Brasília. Anais... Brasília: ABIPTI, 2005. p. 129-132.

SANT'ANNA, J. P. Biodiesel alimenta motor da economia. Química e Derivados, São Paulo, n. 414, abr. 2003. Disponível em: <http://www.quimicaederivados. com.br/revista/qd414/biodiesel1.htm>. Acesso em: 22 ago. 2008. 
SCAIFE, J. R.; MOYO, J.; GALBRAITH, H. Effect o different dietary supplemental fats and oils on the tissue fatty acid composition and growth of female broilers. British Poultry Science, London, v. 35, n. 1, p. 107-118, 1994.

SOUZA, J. C. V. B. Embrapa propõe transformação de gordura animal em biodiesel. Disponível em: $<$ http://www.embrapa.gov.br/imprensa/noticias/2006/ setembro>. Acesso em: 22 dez. 2006.

TRUJILLO-QUIJANO, J. A.; ESTEVES, W.; WIRTH, H. G. Considerações técnico-econômicas sobre o fracionamento de óleo de Dendê. Boletim da Sociedade Brasileira de Ciência e Tecnologia de Alimentos, Campinas, v. 22 n. 1/2, p. 37-53, 1988.
TSUJI, H.; KASAI, M.; TAKEUCHI, H.; NAKAMURA, M.; OKAZAKI, M.; KONDO, K. Dietary medium-chain triglycerides suppress accumulation of body fat in a double-blind, controlled trial in healthy men and women. Journal of nutrition, Philadelphia, v. 131, n. 11, p. 28532859, 2001.

UNIÃO BRASILEIRA DE AVICULTURA - UBA. Relatório anual 2007/2008. Disponível em: <http:// www.uba.org.br>. Acesso em: 22 maio 2008.

UNITED STATES DEPARTMENT OF AGRICULTURE - USDA. Foreign agricultural service. Disponível em: $<$ http://www.usda.gov. $>$. Acesso em: 22 maio 2007.

VIAU, M.; GANDEMER, G. Principales caractéristiques de composition des graisses de volaille. Revue Francaise Des Corps Gras, Paris, v. 38, n. 5-6, p. 171-177, 1991. 
